\title{
“WHEREFORE ARE THESE THINGS HID?"1 A REPORT OF A SURVEY UNDERTAKEN BY THE ARL SPECIAL COLLECTIONS TASK FORCE
}

The conference on Exposing Hidden Collections, hosted by the Association of Research Libraries (ARL) at the Library of Congress in September 2003, was notable for many reasons. Among these were the focus on special collections in the first place; the representation not only from ARL libraries, but also from institutions included in the Oberlin Group of college libraries and the Independent Research Library Association; the expansion of participants to include special collections administrators, library directors, and representatives of foundations and funding agencies; and the emphasis on our dirty little secret, namely, that our libraries collectively hold millions of items that have never been adequately described and therefore are all but unknown to, and unused by, the scholars it is our mission to serve.

The research library community has in large part happily embraced the opportunities provided by new technologies to make certain content in our collections more widely accessible. However, participants in the ARL-sponsored conference expressed clear concern that, by making a priority of digitizing and mounting selective collections on the Web, we were at risk of damning immense quantities of valuable, although perhaps less "sexy," research collections to remain forever unknown. The magnitude and complexity of existing arrearages, the absence of appropriately workable standards to apply to them, and the limited funding available all compound this urgent problem.

Although conference participants agreed that the key to exposing the vast majority of hidden collections is committed local action, there was strong consensus that a national, organized effort to address the

1. Shakespeare's Twelfth Night. 
processing backlogs in library special collections could help individual institutions make progress and also could serve as a test bed for innovative approaches that might be widely emulated or adapted. There was further agreement that, in order to make progress, we would need to devise a structured, systematic method for inventorying and reporting on these backlogs. In order to catalyze action and secure funding, the conference participants recommended that we identify and promote "a shared commitment to certain themes and subjects to encourage cooperative action among libraries and archives" that would work toward eliminating the backlogs of archival, manuscript, rare book, and other special collections in U.S. and Canadian institutions.

\section{Planning for the Survey}

Planning for a focused inventory of special collections arrearages thus became a major agenda item at the October 2003 meeting of the Special Collections Task Force. All agreed that attempting to undertake a comprehensive backlog survey among all the ARL, IRLA and Oberlin Group members was ill advised. After extensive discussion, during which task force members remained mindful of our charge to think about various themes, formats, and time periods around which a focused national effort might begin, the task force decided to issue a call for unprocessed or severely underprocessed special collections in their libraries in one of or more of the following five categories:

- On the theme of women

- On the theme of advertising

- In the format of pamphlets and printed ephemera

- From the period 1865 through 1918 (the end of the Civil War to the end of World War I)

- Highlighting ethnic histories or cultures

Respondents also were invited to identify special collections arrearages in their libraries that they were most eager, for whatever reason, to process, regardless of theme, format, or vintage. In asking this more open-ended question, the task force hoped to surface additional collections of greatest interest to those being surveyed, with the thought that a successful initiative would need to focus on collections that the participants had an enthusiastic commitment to exposing.

Finally, to keep the volume of responses at a manageable number and to force respondents to focus on their most important research collections, 
respondents were limited to no more than three collections in each category. For each collection proposed, libraries were asked to provide brief descriptions, indicating date spans, formats, and extent of volume of material (e.g., "Trade Catalogs, 4,000 titles, 1850-1915" or "Assorted pamphlets, 1773-1976, 7.8 cubic feet"). Although respondents were permitted to submit more extensive descriptions if they existed, the task force was clear in its reassurance that it was not asking potential participants to create new bibliographic records to participate in the survey.

\section{The Survey}

The survey was distributed electronically to all ARL, IRLA and Oberlin Group libraries early in 2004, with a March 15 deadline for responses. The results were much more voluminous than anticipated, indicating a gratifyingly keen interest on the part of respondents. Ninety-nine institutions reported on 466 discrete collections. Respondents included 77 ARL libraries (of which 7 were from Canada), 9 IRLA libraries, and 13 Oberlin Group libraries. The breakdown of responses by categories of collections was as follows: ${ }^{2}$

$\begin{array}{lcc} & \begin{array}{c}\text { Number of } \\ \text { Institutions }\end{array} & \begin{array}{c}\text { Number of } \\ \text { Collections }\end{array} \\ \text { Women } & 59 & 125 \\ \text { Advertising } & 25 & 36 \\ \text { Pamphlets/Ephemera } & 57 & 111 \\ \text { 1865-1918 } & 48 & 87 \\ \text { Ethnic } & 53 & 101 \\ \text { Local Priority } & 87 & 269\end{array}$

Among the themes that emerged most often as "local priorities" (i.e., as those important to the reporting institution but not explicitly included in the task force's questionnaire) were political and social activism, broadcasting, journalism, science and scientists, religion, architecture, transportation, film studies, the American South, and gay and lesbian studies.

The responses were carefully analyzed by a team at Johns Hopkins University's Sheridan Libraries, led by Dawn Hale, Director for Technical Services, and the results presented for discussion and decision at the

2. Most institutions reported more than one collection and many collections were assigned to more than one category.The total number of institutions in the table therefore exceeds 99 and the number of collections exceeds 466. 
Special Collections Task Force meeting in Tucson in May 2004. After reviewing the results, the task force concluded that a project focused on collections relating to political activism and women's rights would be the most likely to garner interest, support, and perhaps funding.-

\section{Next Steps}

Staff at Johns Hopkins have undertaken a more detailed analysis of the collections proposed by the ARL, IRLA and Oberlin libraries in the broad area of political activism and women's rights. The data being compiled will be used as a basis for estimating the costs of a concerted effort to provide "preliminary record" access to the sixty-six collections in this subject area using a MARC-based record format developed by the task force. When the analysis of the survey results is completed, Johns Hopkins will take the lead, on behalf of those libraries who wish to participate, in seeking the funding necessary to create and mount the descriptions that will help make scholars aware of our rich collections in these areas of social and political history.

\section{Next Next Steps?}

Although it would be premature to commit to specific courses of action beyond this initial project, the task force envisions two strands of further activity. First are additional projects to provide preliminary records in areas of great interest to our respondents. These projects would take advantage of the database of information already gathered through the online survey and would build on the experience gained through the first implementation of the preliminary record format. The task force invites readers to review survey responses at http://db.arl.org/SCsurvey/ in order to identify themes for additional projects and to find potential partners for collaborative action. The second activity involves initiatives to preserve and digitize collections included in this initial preliminary records project. Preservation and digitization will ensure that these newly exposed collections are fully usable by the greatest number of researchers and scholars.

Task force members are aware that the preliminary descriptive records that will be created through this project are just one step in that chain of library activities that leads from acquisition to description to preservation to access. But it is a step in the right direction, and one that we must take together and soon. 